\title{
Erratum: Different thresholds of ZEB1 are required for Ras-mediated tumour initiation and metastasis
}

\author{
Yongqing Liu, Xiaoqin Lu, Li Huang, Wei Wang, Guomin Jiang, Kevin C. Dean, Brian Clem, Sucheta Telang, \\ Alfred B. Jenson, Miriam Cuatrecasas, Jason Chesney, Douglas S. Darling, Antonio Postigo \& Douglas C. Dean
}

Nature Communications 5:5660 doi: 10.1038/ncomms6660 (2014); Published 1 Dec 2014; Updated 19 Mar 2015

This Article contains an error in the author contributions section that has resulted in incorrect attribution of experimental planning and manuscript writing to D.S.D. The correct author contributions section is as follows:

Y.L. performed most of the experiments, prepared figures and wrote the manuscript. X.L. performed immunostaining. L.H. and K.C.D. performed real-time PCR. W.W. and G.J. did the lentiviral experiments in the lung. B.C., S.T. and D.S.D. bred mice and collected and analysed lung lesions. A.B.J. and M.C. provided pathology of the mouse and human tumours. J.C. and A.P. planned experiments and commented on the manuscript. D.C.D. planned experiments and wrote the manuscript. 